\title{
UNA LECTURA DEL DESEO FETICHISTA DEL PERSONAJE DE LAS VIOLETAS SON LAS FLORES DEL DESEO Y SU RELACIÓN CON LAS MUÑECAS
}

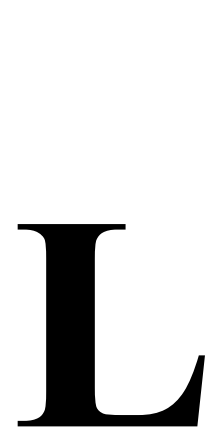

Natalia PLAZA-MORALES

Universidad Cergy Pontoise /USAL

reflexionar acerca del deseo fetichista del personaje de ficción y de su relación con las Violetas, muñecas que se presentan como elementos semánticos convertidos en objetos de perversión para el narrador-protagonista. El sentido que pretendo dar a la temática del juego en esta novela surge como lectura intertextual entre el ámbito del psicoanálisis y de la creación literaria. Así pues, acordamos con Ricœur que el texto es un campo de construcciones posibles que podemos reconstituir, aunque no todas las formas a partir de las cuales se podría interpretar un texto nos aportarían una lectura significativa y substancial del mismo. Esta poética de Ana Clavel podría ser interpretada como una construcción original de una narrativa fantasmática, la cual nos proporcionaría acceso a múltiples lecturas desde el campo del psicoanálisis.

La relación del sujeto al cuerpo está marcada por configuraciones socioculturales e históricopolíticas. En nuestra cultura occidental y de tradición judeo-cristiana, la asociación del cuerpo al deseo conlleva todavía la huella de la prohibición. Los cambios sociales, acontecidos tras la revolución sexual de mediados de los años 60, comportan la transformación de discursos y de comportamientos sobre lo sexual que desatan la puesta en escena de construcciones subjetivas 'otras', en referencia a aquellas manifestaciones que no acompañan a un sistema normativo. Tales producciones, de naturaleza diversa y heterogénea, pueden adquirir múltiples formas: andróginos, fetichistas, transgéneros, androides...Estos imaginarios permiten redibujar el cuerpo y suponen nuevas formas de aprehenderlo, de narrarlo y de pensarlo. Así, no es hasta el final de los años 70, cuando todas estas manifestaciones sexuales se hacen más corrientes. Algunas tendencias no normativas, tales como el sadismo, el fetichismo, el masoquismo y, sobre todo, el tabú del incesto, se convertirán en formas más visibles, aunque siempre fuertemente condenadas. Poco a poco, constatamos la puesta en marcha de espacios 
identitarios que se alejan de una concepción binaria del mundo (naturaleza/cultura), al mismo tiempo que se redefinen universos corporales que podrían pensarse a través de toda una serie de cuestiones de diversa índole: emotivas, sensoriales, estéticas...

En esta óptica de pensamiento, El Manifiesto Cyborg (1984), publicado por Donna Haraway, constituye una obra fundamental. Según la filósofa americana, podríamos imaginar otras realidades sociales y culturales. El cyborg sería la metáfora de un mecanismo que nos anima a reconstruir nuevas identidades para repensar el cuerpo. Un tal estudio, escrito bajo el tono del sarcasmo, trataría de pensar aquellas formas que habrían sido abordadas por la tradición como referentes al 'Otro', a diferencia del conjunto heteronormativo. Ya se trate de un cuerpo perverso, fetichista, o, simplemente del cuerpo de mujer, todas estas dimensiones han sido consideradas como distintas al discurso logocéntrico. Para Haraway, el mito del Cyborg sería un ser ejemplar de la era tecnológica, una entidad concebida a medio camino entre la naturaleza humana y el animal, es decir, una especie de máquina-viviente de esencia híbrida, alejada de toda distinción. En este sentido, la metáfora del cyborg simboliza la idea de tener en mente la disolución de las fronteras vinculantes entre lo natural y lo artificial, el cuerpo y el espíritu, el sexo y el género:

El Cyborg se sitúa decididamente del lado de la parcialidad, de la ironía, de la intimidad y de la perversidad. Es opositivo, utópico y en ninguna manera inocente. Al no estar estructurado por la polaridad de lo público y lo privado, define una polis tecnológica basada parcialmente en una revolución de las redes sociales en el oikos, la célula familiar. La naturaleza y la cultura son remodeladas y la primera ya no puede ser un recurso dispuesto a ser apropiado e incorporado por la segunda (Haraway, 1984: 4).

La literatura y las artes, así como las tradiciones populares, han contribuido de manera general a enriquecer el mito de la muñeca. Este cuerpo artificial permite establecer un discurso que se extiende hacia una perspectiva más amplia de posibilidades. Tal y como lo explica Martine Lusardy (2006), este objeto inanimado sería un instrumento de connotaciones múltiples. Antes de convertirse en un juguete privilegiado para el niño, también ha sido el símbolo de rituales en numerosas tribus antiguas. La significación de este utensilio es diversa, depende de la mentalidad de aquellos que van a hacer uso de tales creaciones. Así, por ejemplo, podríamos señalar que las muñecas de Kachina son uno de los signos más relevantes de la cultura india de Nuevo México: figuras místicas representativas de un pueblo que idolatra este objeto no natural como fuente de desarrollo espiritual (Lusardy, 2006: 9-16).

Es interesante señalar el papel significativo que ocupa la muñeca en el género literario. No son pocos los relatos en los que, sin tratarse de la protagonista de la ficción, estamos ante un objeto que marcará la manera de percibir la infancia de los personajes. A propósito, Michel Manson (2002) lleva a cabo un estudio de algunas narraciones de Víctor Hugo o de Rousseau para hablar del mito de este juguete tan particular. En Los Miserables (1862), Víctor Hugo describe la identificación de la infancia femenina con la subjetividad de la muñeca, un objeto que viene a representar el primer modelo femenino para la mujer. De esta forma, la muñeca se convierte en un ser intermediario entre su hija Colette y la evolución, desde niña, de la identidad femenina:

La muñeca es una de las necesidades más imperiosas y, al mismo tiempo, uno de los instintos más encantadores de la infancia femenina. Cuidar, cubrir, vestirse, desvestirse, enseñar, regañar, balancear, 


\section{Tropelías. Revista de Teoría de la Literatura y Literatura Comparada, 29 (2018) \\ Una lectura del deseo fetichista del personaje de Las violetas son las flores del deseo... \\ mimar, dormir, imaginar que algo es alguien, todo el futuro de la mujer está allí. (Les Miserables de Victor \\ Hugo, 321, citado por Michel Manson 64-87; la traducción es nuestra).}

Desde el punto de vista de la connotación sociocultural asociada a este juguete, la muñeca sería para Simone de Beauvoir el alter ego de la niña, el objeto que marca la construcción del rol pasivo de la mujer y su función reproductora, un utensilio que permite a la niña remplazar la carencia de un 'juguete' que sería exclusivo del sexo masculino, es decir, Beauvoir hablará del órgano masculino. En El segundo sexo (1949), la filósofa revela los instintos masculinos y femeninos como el resultado de aquellos comportamientos y rasgos del carácter que tienen su respuesta en un fuerte componente cultural: «Entre las jóvenes y los varones el cuerpo es, en primer lugar, la irradiación de una subjetividad, el instrumento que realiza la comprensión del mundo: el universo es apresado a través de los ojos o las manos, pero no por las partes sexuales» (Beauvoir, 1949: 13).

Es así como la filósofa francesa describe la relación que tradicionalmente han conservado los sexos normativos con los objetos. La muñeca sería ese ser inanimado al cual se encuentra siempre atado la mujer desde la infancia, como si se tratase de una prolongación de sí misma, y cuya relación con este utensilio se desvela de un comportamiento cultural:

En compensación, le ponen entre las manos, con el fin de que desempeñe junto a ella el papel de alter ego, un objeto extraño: una muñeca. Es preciso notar que también se llama poupée («muñeca») a ese vendaje con que se envuelve un dedo herido: un dedo entrapado, separado, es mirado con regocijo y con una especie de orgullo, y el niño esboza con respecto al mismo el proceso de alienación. Pero una figurilla con rostro humano, o en su defecto una mazorca o un palo, reemplazará de la manera más satisfactoria a ese doble, a ese juguete natural que es el pene. (1949: 116)

Como vemos, el imaginario del cuerpo de la muñeca puede conducirnos hacia múltiples campos de análisis. Recordemos el estudio llevado a cabo por Freud en «Das Unheimliche» (1919). Un texto con pretensiones estéticas donde el psicoanalista alemán nombra a algunos autores que han hablado de la muñeca como un objeto 'animado' que adquiere una naturaleza extraña, difícil de delimitar. Freud recupera las palabras de E. Jentsch con respecto a sus consideraciones de tal ser inerte y la sensación de estar vivo:

E. Jentsch destacó, como caso por excelencia de lo siniestro, la duda de que un ser aparentemente animado, sea en efecto viviente; y a la inversa: de que un objeto sin vida esté en alguna forma animado», aduciendo con tal fin, la impresión que despiertan las figuras de cera, las muñecas «sabias» y los autómatas (1919: 14).

Para explicar una estética de lo Unheimliche, el psicoanalista alemán cita a Hoffmann y pone de relevancia algunos de sus cuentos fantásticos. Entre estos, nos sugiere centrarnos en la muñeca Olimpia, un ser artificial que adquiere dimensiones reales para el personaje del cuento. La sensación de extrañeza que provoca la muñeca Olimpia se encuentra en relación con una percepción psíquica y visual. Freud nos propone una explicación psicoanalítica a la metáfora de los ojos, en tanto que imagen textual que vincularía la pérdida de la vista con el sentimiento de castración y con el Complejo de Edipo en el niño. Para el psicoanalista alemán, lo que nos llevaría hacia una sensación de lo ominoso en este cuento, se atribuiría, por un lado, a la naturaleza animada de Olimpia, pero, sobre todo, el 
aspecto clave que marcaría tal estética estaría en relación con los ojos, que se desvelarían como una fuerza poderosa que hace emanar angustia y miedo (Freud 1919: 14). De tal modo que, la figura de Olympia se convertiría en la fuente de un deseo infantil y no en la causa del miedo a la castración (1919: 19).

A continuación, pensamos el cuerpo artificial de la muñeca en la novela de Ana Clavel como una representación subjetivada por el personaje fetichista de esta ficción. En Las Violetas son las flores del deseo (2007), la muñeca cumple la función de una fuente de un deseo que tiene como canal erótico la mirada. El cuerpo artificial de las Violetas se convierte en un estímulo con el que fantasmea el narrador-protagonista de esta ficción. El sentido que toma la muñeca para el personaje se presenta más allá de la definición tradicional del cuerpo, que, recordemos, de acuerdo con el diccionario de la RAE se definiría como materia «de extensión limitada, perceptible por los sentidos». Julián Mercader instaura una especie de vínculo afectivo con estos objetos de plástico, seres inertes que parecen cobrar vida a través de las fantasías del personaje perverso. Las Violetas se convierten no sólo en elementos de erotismo sino en cuerpos abstractos de naturaleza ambivalente. Estos objetos permiten apaciguar aquellas sensaciones extremas experimentadas por el personaje principal a través de la mirada, unas apetencias que estarían dirigidas en principio a un objeto real, su hija Violeta: «Pero mirarla frente a frente, sostenerle la mirada, sería como abandonarse a la muerte: asomarse a su espejo de abismos y éxtasis» (Clavel 2007: 64).

Para imaginar la forma según la cual el personaje masculino se proyecta con el uso de las muñecas en la novela de Clavel, nos acercamos a la concepción del cuerpo desarrollada por MerleauPonty. El pensamiento del filósofo francés evoluciona hacia la construcción de una ontología del ser que se lograría a partir de una cohesión experimentada entre la percepción y la manera en que el hombre cohabita con todo lo que le circunda. El ser y el mundo físico transcienden en una misma dimensión, es decir, el sentido (percibir) y el sentir (percepción) no serían entidades ontológicas que se oponen o se limitan: «El espesor del cuerpo, lejos de rivalizar con el del mundo, es, por el contrario, el único medio que tengo para ir hasta el corazón de las cosas, convirtiéndome en mundo y convirtiéndolas a ellas en carne» (Merleau-Ponty, 1964: 176).

Las muñecas de la ficción de Clavel parecen ser objetos de naturaleza indefinida y extraña, a veces perversas, en ocasiones dulces y angelicales. Las Violetas marcan, por una parte, la inocencia del juego de niños, por otra, estos seres son el puente hacia la iniciación a la sexualidad y otras manifestaciones de deseo que surgen en Julián Mercader y aquellos personajes masculinos del relato que también disfrutan de este juguete:

Aunque, a decir verdad, no siempre las Violetas fueron perversas. En las dimensiones y tamaños habituales, con sus rostros acorazonados, sus cuerpos pre púberes, enfundadas lo mismo en atuendos de princesas con vestidos de etiqueta y peinados altos, que al último grito de la moda con minifaldas y melenas ensortijadas, las Violetas actuaban tan a la perfección en su papel de niñas precoces pero siempre bien portadas, que no hubo en el país otra línea de muñecas que se mantuviera a la par de los modelos extranjeros que por ese entonces comenzaron a inundar el mercado nacional ( Clavel, 2007: 27). 
A propósito del carácter ambivalente con el que se describen las muñecas de Clavel, Teresa López-Pellisa nos acerca desde el género literario a la relación marcada entre el personaje masculino y cuerpo artificial femenino. Para ello, esta crítica recurre a los mitos de Pigmalión y de Pandora. Durante la antigua Grecia, el escultor Pigmalión labra una figura femenina que se concibe como la imagen idílica de sí mismo proyectada en el sexo opuesto. Hablar del mito de Pandora supone recuperar el arquetipo de la mujer fatal, es decir, tener en mente a un ser poderoso que posee cualidades tanto embaucadoras como nefastas para el hombre (López -Pellisa, 2005: 194-6).

En esta óptica, las muñecas de Clavel son creadas por Julián Mercader a semejanza de su hija Violeta, poseen, pues, un cuerpo femenino real como modelo de referencia único para el personaje masculino: «A veces, al imaginar la dulzura de sus pequeñas insolentes, me he preguntado cuáles pudieron ser los suyos. Por supuesto, sé desde siempre que su único nombre verdadero - ese que le pertenece a cada uno más allá de la confusión y la apariencia - es justamente Violeta. La irremediablemente violada. ¿Verdad que no me equivoco? »(Clavel, 2007:47).

\section{El juego de Las Violetas y el personaje perverso}

El relato homodiegético del narrador-protagonista de esta novela comienza in medias res, al rememorar aquellos recuerdos de infancia, entre los cuales, la muñeca aparece como un elemento clave para el desarrollo de la futura sexualidad de Julián Mercader:

\footnotetext{
Digamos que mi destino estuvo trazado antes de mi nacimiento. De manera particular, cuando el recién casado que sería mi padre decidió invertir la herencia de los abuelos en una fábrica de muñecas. Ignoro cuándo, en el correr de pañales y pasos, se decidió a llevarme a la fábrica, pero debió ser más tarde, cuando mi madre dio señales de quedar nuevamente embarazada (Clavel, 2007: 18).
}

La semántica de esta ficción evidencia de la relación entre el juego de niños y el carácter sexual concedido a esta actividad lúdica. La razón por la cual Julián Mercader padre, dueño de una fábrica de muñecas, lleva a Julián Mercader hijo a este lugar, podría darse por sobreentendida gracias a la imagen textual puesta en marcha por la escritora mexicana, quien parece dirigir dicho juego de muñecas hacia una dimensión crucial para la futura sexualidad del personaje masculino: la identidad perversa. A lo largo de este pasaje, el personaje utiliza el término 'inofensivo' para designar el lugar donde su padre le expone al juego siendo niño. Esta semántica acentúa ya la simbolización que la acción de jugar va a ir adquiriendo a lo largo de la narración. Sólo, alejado del mundo exterior, Julián Mercader hijo descubre el mundo de las muñecas:

Por eso, porque me estaba criando entre demasiadas mujeres, Julián Mercader, mi padre, apenas tuve edad suficiente, se decidió a llevarme a sus terrenos e introducirme en el mundo de carruseles y bandas mecánicas en el que se articulaban los fragmentos de cuerpos de muñecas. Y me dejaba ahí, como si me depositara en un inofensivo jardín de niños, en el que se suponía habría de entretenerme y asombrarme sin cuento mientras se cumplía el plazo para asistir al colegio (2007: 18).

Esta idea astuciosa de Ana Clavel, que consiste en contextualizar la aparición de la muñeca y la relación con la sexualidad infantil del personaje, constituye una noción primordial para la clínica real. 
Recordemos cómo, según la teoría psicoanalítica en general, el juego tenía una función fundamental para el desarrollo del niño. En este sentido, Donald Winnicott, psiquiatra y psicoanalista inglés, afirma que: «Es al jugar, y seguramente sólo mientras está jugando, cuando el niño o el adulto se libran a la creatividad» (1975: 108; la traducción es nuestra). Asimismo, según Freud, el juego permite al niño mimar su posición de adulto: «El niño juega siempre a ser 'adulto'; imita en el juego lo que será de facto llevado a conocer más tarde» (1919: 31). Para el psicoanalista inglés, la reinversión de roles entre el niño y el adulto necesita alejarse de toda situación de dominación o de autoridad: «Cuando un organizador es llevado a dirigir el juego del niño, esto implica que los niños son incapaces de jugar en el sentido creativo como yo expongo aquí» (1975: 103; la traducción es nuestra).

Un nuevo personaje entra en acción en la historia de ficción, Klaus Wagner, individuo enigmático a quien el padre va a confiar la custodia de Julián Mercader mientras se encuentra en la fábrica de muñecas. Klaus Wagner se encarga de supervisar las producciones de las muñecas. Pero este personaje es también, quien, desde una edad temprana, inicia al protagonista al placer que le puede proporcionar la visualización del cuerpo desarticulado de estos seres inertes. Es precisamente Klaus Wagner quien 'olvida' cerrar la puerta con llave de una habitación secreta donde el protagonista de la novela entra en contacto con las imágenes perversas de las muñecas:

Y para guiarme y enseñarme mientras esto sucedía confió mis visitas a la fábrica a un hombre de mirada azul que diseñaba y supervisaba la producción de juguetes, amigo de la carrera de papá, su socio alemán que había crecido en México después de la segunda guerra y estudiada ingeniería química por las mañanas y dibujo artístico por las tardes: Klaus Wagner. Recuerdo que la mirada azul de Klaus Wagner solía intimidarme: su transparencia me hacía pensar que sus ojos no tenían fondo y que en consecuencia nada podía ocultárseles. Tiempo después, cuando adolescente, comencé a descubrirme deseos y apetitos desconocidos, supe que había tenido razón en creer que nada escapaba a su mirada. Y de hecho fue gracias a él, quien olvidó un día cerrar con llave esa suerte de cuarto oscuro habilitado en un clóset de su privado, que descubrí las imágenes contagiosas de Bellmer (Clavel, 2007: 19).

Sin embargo, lo que Julián Mercader había supuesto siendo un niño como una negligencia de su mentor, es reinterpretado ahora, en la adultez y entre recuerdos, como el medio utilizado por Klaus Wagner para probar la verdadera naturaleza perversa del protagonista:

Ahora sé que no hubo descuido, que lo hizo para probarme, para conocer mi madera de árbol petrificado ante el asombro de todo aquello que insinuara una inocencia mancillada. Pero para entonces pasarían largos años de entrenamiento e iniciación, marcados en principio por mi incapacidad de abstraerme en la contemplación de los miembros todavía inarticulados de las muñecas que desfilaban en las bandas mecánicas antes de ser ensamblados para conformar ejemplares en serie que harían las delicias maternales de las niñas anónimas y distantes (2007: 19).

Las Violetas van a ser estos instrumentos compartidos por otros personajes masculinos para desplazar un objeto de deseo. Si pasamos por la teoría psicoanalítica freudiana, la explicación para este comportamiento se encontraría en que, durante el proceso psíquico de la sublimación del deseo, el sujeto que desea intensamente un objeto inalcanzable se vuelca hacia otro propósito que podríamos afirmar como más artístico, retomando los postulados Freud en sus Tres ensayos sobre la teoría de la sexualidad (1905). En este sentido, podríamos pensar que la puesta en marcha narrativa de este proceso de sublimación se mostraría en la historia de ficción de Clavel como un instrumento positivo para no 
transgredir la norma: «No pretendo engañar a nadie al decir que busqué consumar en las Violetas una pasión que me abrazaba las entrañas, en vez de dirigirme hacia el objeto real que la despertó tan despiadadamente» (Clavel, 2007: 47).

Tal vía de satisfacción tomaría la forma de la producción artística con una creación real: las Violetas, figuras femeninas que sirven para satisfacer los deseos masculinos. Dichas obras plásticas ya no pertenecen al ámbito exclusivo del fantasma y pueden ser contempladas, admiradas, convertirse en objeto de valoración y de miradas deseosas. Tal propósito se logra en la novela con la creación de estas muñecas clandestinas, construidas por el personaje con esmero, en búsqueda de la perfección. Estos seres artificiales van a deleitar los apetitos perversos de otros hombres. Así, Helisberto Hernández surge como un personaje misterioso, una especie de voz reflexiva que podemos leer como afín a la parte instintiva de la personalidad psíquica freudiana del 'Ello'. Podríamos interpretar este personaje desde la intertextualidad con el psicoanálisis, en tanto que una entidad cercana al ámbito del imaginario. Helisberto Hernández será quien revele al protagonista de la ficción la intensidad de los abismos de un deseo perverso, aquel que tiene origen en una pasión inalcanzable:

Aunque no nos atrevamos a decirlo, toda pasión tiene un nombre y un origen cercanos. A veces, al imaginar la dulzura de sus pequeñas insolentes, me he preguntado cuales pudieron ser los suyos. Por supuesto, sé desde siempre que su único nombre verdadero- ese que le pertenece a cada quién más allá de la confusión y la apariencia- es justamente Violeta. La irremediablemente violada. ¿Verdad que no me equivoco? (2007: 47).

Podríamos sugerir la caracterización del personaje adulto y su relación con las Violetas en relación con los postulados freudianos sobre el juego. Para Freud, el jugar para el adulto puede convertirse en una actividad 'extraña', sin correlación entre la realidad y el fantasma (1908: 36-37). Es interesante pasar por las conceptualizaciones de Lacan, quien afirma que la sublimación es un proceso que se efectúa en el mundo de las fantasías particulares del sujeto perverso. Dicho estado sólo puede existir en el dominio del fantasma. La teoría lacaniana aporta luz al concepto freudiano y lo ambiciona como un proceso que nos permite poner en relación la oposición naturaleza/ cultura. El objeto sublimado es un instrumento aceptado socialmente, no constituye un peligro, se trata de un mecanismo construido por el hombre, entonces, resulta del dominio de lo externo, de la autoridad, de la consciencia moral. Las cuestiones de la sublimación son del ámbito del imaginario social y la explicación que nos da Lacan de este transfer del deseo se encuentra anclada en el campo de la consciencia moral. De este modo, la sublimación sería para Lacan una especie de 'pacto' acordado entre las ilusiones engañosas de la pulsión y las exigencias de la consciencia. Esta noción se puede extender también a las muñecas como elementos fetiches en esta ficción de Clavel. El personaje transmite al lector la idea, según la cual, por medio de la sublimación, sus deseos no pueden ser considerados como ilícitos. Esta narración se sitúa en el campo del Otro, es decir, se dirige al lector cuando implora todas aquellas entidades ficcionales que condenan un deseo sublimado que no es transgredido en cuanto a la acción: « [Q]uiero repetirlo una vez más, mi crimen no es del todo un crimen, aunque tampoco, lo reconozco, puedo declararme inocente $¿ \mathrm{O}$ es que acaso alguien se atrevería a condenar a Hans Bellmer por haber soñado sus muñecas? »(Clavel, 2007: 35). 
De esta forma, el discurso de Julián Mercader se presenta cada vez más cercano a lo patológico, el personaje se evade del mundo con su pasión por construir muñecas, hasta el punto de llegar a escuchar las voces y peticiones de estos objetos en un acto de sublimación que las humaniza, pero que, a su vez, conduce al personaje a deformar la realidad:

También es cierto que cada vez eran más flexibles y complacientes [...] Pero yo no me daba abasto: eran ya cinco y no podía cumplirle a cada una, darles su ración de atención y cuidados. A su modo silencioso me lo hacían saber: un descendimiento de párpados inesperado, el movimiento lateral de un rostro como negándose a participar en los rituales y en los juegos (2007: 94).

Julián Mercader se desvincula progresivamente de otros personajes, comenzando por su hija Violeta (primer objeto de deseo), a medida en que la pasión desmesurada de éste por las muñecas se hace más intensa. El personaje niega igualmente la realidad concreta, imagina mantener una relación trascendental con estos seres de plástico:

Mi vida se había teñido de violetas, impregnado de su aroma irrenunciable. Era sin duda alguna el más feliz de los mortales. Nada me perturbaba, ni los cambios que atormentaban al país, ni las vicisitudes de los que tienen que proveer el diario alimento a sus familias, ni el reconocimiento que hace delirar a los soberbios de mafias y cofradías... (2007: 103).

Incluso su instructor al deseo perverso, el personaje de Klaus Wagner, parece advertir que los abismos del deseo y la obsesión por las muñecas adquieren una dimensión peligrosa que va más allá del dominio de la fantasía, tal y como si Julián Mercader se precipitase hacia la perversidad más oscura, desatase su instinto más irracional:

Creo que Klaus, a quien pocas cosas podían perturbar, tampoco se lo esperaba. Recordé su mirada cristalina que muy tempranamente, muy cercano el episodio de Naty y mi fascinación primera por los miembros inarticulados de las muñecas, me había reconocido con un leve gesto de bienvenida hacia una multitud de iguales donde mi padre y el propio Klaus Wagner me darían cabida tarde o temprano. Pero en esta ocasión la mirada del hombre que otras veces había fungido en mí un segundo padre, a su modo y en su reticencia más accesible que el otro, me contemplaba con un gesto inusual, sorprendido de verme avanzar en el camino de los deseos donde al parecer él hacía tiempo se había detenido (2007: 82-83).

\section{Conclusiones: Leyendo cuerpos}

En Antropología del cuerpo (2004), Mari Luz Esteban propone pensar el cuerpo como agente y no en tanto que objeto. La crítica literaria española medita un cambio de percepción de la realidad, que consistiría en adentrarnos en nuestra existencia a través de la multiplicidad de cuerpos a los cuales el sujeto puede acceder gracias a su diversidad: «Pasar de considerar el cuerpo como un objeto a considerarlo como un sujeto, a identificar yoes y cuerpos, a leer y escribir también de otra manera las trayectorias vitales, sin dejar a un lado su materialidad ni observar los cuerpos desde fuera, y asumiendo por tanto las consecuencias que de ello se derivan» (Esteban, 2004: 11).

Para ello, un buen ejercicio de análisis estaría en ofrecer nuevos enfoques que piensen el cuerpo desde la experimentación. Todo pensamiento de la corporalidad ya sea social, estético o incluso político, debe transcender una concepción genérica y profundizar en un imaginario por el cual, la ambición de tales representaciones corporales sea más amplia y positiva, menos limitada y de carácter 
homogéneo (Esteban 2004: 30-32). Como lo sugiere Esteban, es importante poder considerar una visibilidad real de una práctica individual, con el fin de concretizarla en un sentido más amplio:

Si no somos capaces de evocar, de ponerle cuerpo/ imagen a un tipo concreto de reinvindicación, o nos cuesta, es que hay algún grado de invisibilización o dificultad alrededor de ese campo, de esa reinvindicación, o nos cuesta, es que hay algún grado de invisibilización o dificultad alrededor de ese campo, de esa reinvindicación, que va más allá de su oportunidad teórica o política (2004: 52).

En esta óptica de lectura, la cual se enmarcaría en un pensamiento de esencia estructuralista, el espíritu, la mente, ya no es un obstáculo para repensar el cuerpo, que suele concebirse siguiendo las determinaciones que nos impone la cultura y la sociedad. Esta nueva visión del cuerpo conllevaría también el poder ir más allá de la distinción naturaleza/ cultura. Debido a todas estas representaciones genuinas que nos ofrecen el arte y la literatura, podemos acordar al cuerpo nuevos espacios y ambiciones, orientándolo hacia la consecución de valores más neutros, en particular al cuerpo de mujer, que no debemos olvidar, continúa marcado por una tradición que lo opone al cuerpo masculino. Tal y como lo declara Luisa Posada Kubissa, habría que saber hacer resurgir un discurso femenino más allá de aquel que ya está establecido, con el objetivo de conducir al sujeto hacia una concepción de la corporalidad mucho más universal:

Se trata de pensar el cuerpo de otra manera y de disociarlo de la identificación con lo femenino. Porque, de otro modo, quedaríamos presas de ese discurso patriarcal que veta a las mujeres su capacidad de trascendencia. Una trascendencia que ha de estar guiada por los intereses en un mundo mejor, desde una lógica que aspire a no reproducir sin más las coordenadas dominantes de pensamiento. Se trata, en fin, de revalorizar para todos/todas una ética del cuidado y de la solidaridad, unas relaciones de inter-dependencia, que, más allá y más acá de su cuerpo, las mujeres conocen y pueden enseñar (2015: 121).

Las muñecas son cuerpos que también han sido ejemplo de la puesta en marcha de una visión tradicional del cuerpo femenino, pero que pueden reformularse a medida en que se piensan nuevas formas de concebir el cuerpo artificial y el sentido de lo erótico femenino. Por ello, es interesante mencionar cómo Clavel, con sus genuinas representaciones corporales, ha indagado en lo que ella llama una especie de 'transliteratura', con la intención de experimentar con sus ideas más allá del texto mismo. Así, «El origen del juego» es el nombre que la autora ha elegido para una instalación que homenajea conceptualmente el arte de Bellmer, a Duchamp con su obra Étant donné y a Courbet con El origen del mundo. Las piernas de una muñeca pueden ser la fuente de un objeto de deseo para aquel que las contempla de manera perversa. 


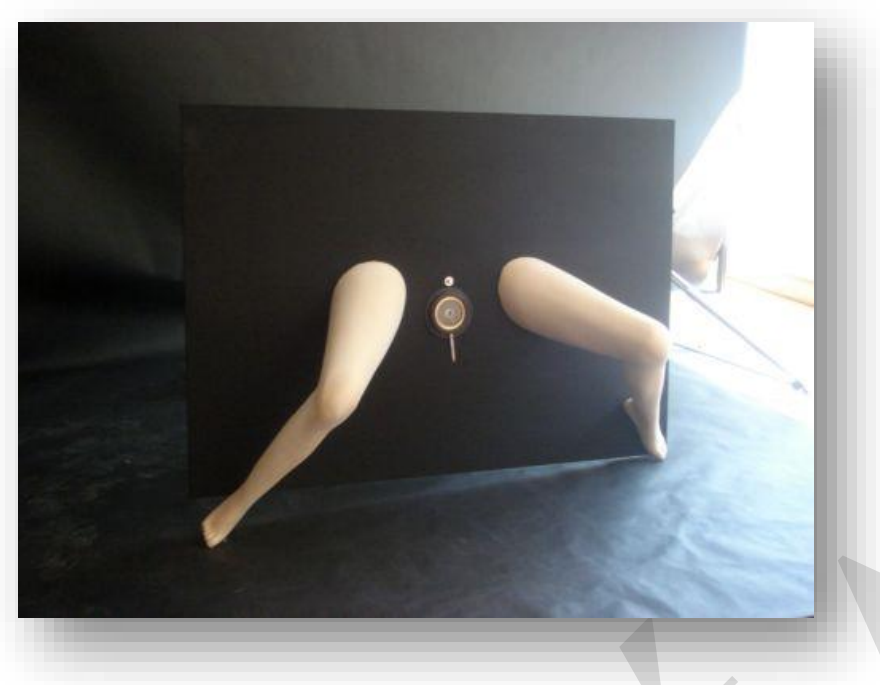

El origen del juego: «Dados Courbet, Duchamp, Bellmer» ${ }^{\mathbf{1}}$. Fotografía: Rogelio Cuellar.

Tras la reflexión sobre el cuerpo de la muñeca en Clavel y en otros autores que han servido a dar consistencia a este análisis, podríamos concluir este trabajo con los siguientes interrogantes: las muñecas, ¿son representaciones del tabú o seres angelicales? ¿Qué relación existe entre la muñeca y el cuerpo de mujer? La infancia, ¿es el momento clave para aprehender lo que deseamos y la manera en que percibimos una subjetividad que nos es propia?

\section{Referencias bibliográficas}

BINET, A. (1887): Le fétichisme dans l'amour. F. V. Éditions, Version Kindle, 2014.

Clavel, A. (2007): Las violetas son las flores del deseo. México, Alfaguara.

De BeauvoIR, S. (1949): Le deuxième sexe. Paris, Ed. Gallimard, 2010.

EFE (2007): «La mexicana Ana Clavel explora los límites del incesto», Soitu.es, en http://www. soitu.es/soitu/2007/11/12/info/1194895007_635264.html (última consulta, 19-12-2017).

EstebAn, M. (2004): Antropología del cuerpo. Barcelona, Bellatera.

FREUD, S. (1905): Trois essais sur la théorie sexuelle. Trad, Philippe Koeppel. Paris, Gallimard, 2001. (1908): «El poeta y los sueños diurnos», en http://www.biblioteca.org.ar/libros/211753.pdf (última consulta, 19-12-2017).

(1919): Lo siniestro, en https://www.ucm.es/data/cont/docs/119-2014-02-23-Freud.LoSinies tro.pdf (19-12-2017).

Haraway, D. (1984): Cybord Manifesto. Trad. Beatriz Suarez, en https://xenero.webs.uvigo.es/ profesorado/beatriz_suarez/ciborg.pdf (última consulta, 19-12-2017).

\footnotetext{
${ }^{1}$ Instalación disponible en la página web de la autora: https://www.violetasfloresdeldeseo.com/ (última consulta, 19-122017).
} 
LACAN, J. (1959-1960): L'Éthique de la psychanalyse, Livre VII. Le séminaire de Jacques Lacan. Paris, Seuil, 2010.

LÓPEZ-PELliSA, T. (2005): Patologías de la realidad virtual: Cibercultura y ciencia ficción. Madrid / México, Fondo de Cultura Económica.

LuSARDI, M. (2016): «Ces poupées qui ne veulent pas être que des jouets», Cahiers Jungiens de Psychanalyse, 117, pp. 9-16; en https://www.cairn.info/revue-cahiers-jungiens-de-psychana lyse-2006-1-page-9.htm (última consulta, 19-12-2017).

Manson, M. (2002): «La Poupée de Cosette, de la littérature au mythe», en Evelyne PoIREL (dir.), Lorsque l'enfant paraît... Victor Hugo et l'enfance. Paris, Somogy, pp. 64-87.

PONTY, M. (1964): Le visible et l'invisible. Paris, Gallimard, 2014.

PoSADA KuBISSA, M. L. (2015): «Las mujeres son cuerpo: reflexiones feministas», Investigaciones

Feministas, 6, pp. 108-121; en https://revistas.ucm.es/index.php/INFE/article/viewFile/51382/ 47662 (última consulta, 19-12-2017).

WinnicotT, D. W (1975): Jeu et réalité. Trad. Claude Monod y J.-B. Pontalis. Paris, Folio. 